\title{
Change in dust variability in the Atlantic sector of Antarctica at the end of the last deglaciation
}

\author{
A. Wegner ${ }^{1}$, P. Gabrielli ${ }^{2,3}$, D. Wilhelms-Dick ${ }^{1, *}$, U. Ruth ${ }^{4}$, M. Kriews ${ }^{1}$, P. De Deckker ${ }^{5}$, C. Barbante ${ }^{2,6}$, G. Cozzi $^{2,6}$, \\ B. Delmonte ${ }^{7}$, and H. Fischer ${ }^{1,8,9}$ \\ ${ }^{1}$ Alfred Wegener Institute for Polar and Marine Research, Am Alten Hafen 26, 27568 Bremerhaven, Germany \\ ${ }^{2}$ Institute for the Dynamics of Environmental Processes, CNR, 30123 Venice, Italy \\ ${ }^{3}$ School of Earth Science and Byrd Polar Research Center, The Ohio State University, Columbus, OH 43210-1002, USA \\ ${ }^{4}$ Climate Analysis and Consulting, Pfullingen, Germany \\ ${ }^{5}$ Research School of Earth Sciences, The Australian National University, Canberra, ACT 0200, Australia \\ ${ }^{6}$ Department of Environmental Sciences, University Ca' Foscari of Venice, Dorsoduro 2137, 30123 Venice, Italy \\ ${ }^{7}$ DISAT - Department Environmental Sciences, University Milano Bicocca, 20126, Milan, Italy \\ ${ }^{8}$ Climate and Environmental Physics, Physics Institute, University of Bern, Sidlerstrasse 5, 3012 Bern, Switzerland \\ ${ }^{9}$ Oeschger Institute for Climate Change Research, University of Bern, Bern, Switzerland \\ *now at: University of Bremen, Klagenfurter Strasse, Bremen, Germany
}

Correspondence to: A. Wegner (anna.wegner@awi.de)

Received: 5 January 2011 - Published in Clim. Past Discuss.: 18 February 2011

Revised: 24 August 2011 - Accepted: 27 October 2011 - Published: 19 January 2012

\begin{abstract}
We present a Rare Earth Elements (REE) record determined on the EPICA ice core drilled at Dronning Maud Land (EDML) in the Atlantic sector of the East Antarctic Plateau. The record covers the transition from the last glacial stage (LGS) to the early Holocene (26600-7500 yr BP) at decadal to centennial resolution. Additionally, samples from potential source areas (PSAs) for Antarctic dust were analyzed for their REE characteristics. The dust provenance is discussed by comparing the REE fingerprints in the ice core and the PSA samples. We find a shift in variability in REE composition at $\sim 15000 \mathrm{yr} B \mathrm{P}$ in the ice core samples. Before $15000 \mathrm{yr} \mathrm{BP}$, the dust composition is very uniform and its provenance was most certainly dominated by a South American source. After $15000 \mathrm{yr}$ BP, multiple sources such as Australia and New Zealand become relatively more important, although South America remains the major dust source. A similar change in the dust characteristics was observed in the EPICA Dome $\mathrm{C}$ ice core at around $\sim 15000 \mathrm{yr} \mathrm{BP}$, accompanied by a shift in the REE composition, thus suggesting a change of atmospheric circulation in the Southern Hemisphere.
\end{abstract}

\section{Introduction}

Dust deflated from arid and semiarid continental areas and deposited on ice sheets at high latitudes is used as a tracer of past atmospheric dust load, with higher dust concentrations during glacial times (e.g. Lambert et al., 2008). An understanding of the dust provenance is crucial for the correct interpretation and accurate modeling of dust records from ice cores; however, recent models still fail to reproduce quantitatively the large glacial-interglacial difference in dust deposition to high latitudes by an order of magnitude (e.g. Mahowald et al., 2011). In Antarctica, most of the studies on dust provenance have been carried out on ice cores extracted from the Indian Ocean sector of the East Antarctic Plateau (EAP) and are based on $\mathrm{Sr}, \mathrm{Nd}$ and $\mathrm{Pb}$ isotopic fingerprinting (Revel-Rolland et al., 2006; Delmonte et al., 2008; Vallelonga et al., 2010), rare earth and trace elements (Gabrielli et al., 2005a,b; Gaspari et al., 2006; Gabrielli et al., 2010), particle induced X-ray emission (Marino et al., 2008), magnetic properties (Lanci et al., 2008), or single element analysis (Siggaard-Andersen et al., 2007). A few studies were

Published by Copernicus Publications on behalf of the European Geosciences Union. 
performed on peripheral areas of the Antarctic continent (Berkner Island, Bory et al., 2010 and Talos Dome, Delmonte et al., 2010b). Overall, these studies indicate the southern South American continent was the major dust source during glacial times, although minor contributions from Antarctic or Australian sources cannot be ruled out (Revel-Rolland et al., 2006; De Deckker et al., 2010). A detailed study based on $\mathrm{Sr}$ and $\mathrm{Nd}$ isotopes revealed that the Patagonian region is the major dust source during glacials, although a small contribution from high-altitude South American sources located at lower latitudes is also possible (Gaiero, 2007; Delmonte et al., 2010a).

Dust provenance identification for interglacial stages is much more difficult due to the lower dust fallout to Antarctica, but preliminary evidence points to southern South America becoming less important relative to Antarctic or Australian sources during the Holocene (Revel-Rolland et al., 2006; De Deckker et al., 2010; Gabrielli et al., 2010). At that time, the contribution from local sources became important for peripheral sites such as Talos Dome, located in the Indian sector of the East Antarctic plateau (EAP, Delmonte et al., 2010b).

Studies of dust provenance in the Atlantic sector of the EAP are scarce. However, due to its location (downwind of Patagonia), the region is likely influenced by dust originating from South America, as supported by back trajectory and modeling studies (Reijmer et al., 2002; Li et al., 2008). Marino et al. (2009) identified a common provenance during glacial stages in the two ice cores from Dronning Maud Land (EDML) and Dome C (EDC) drilled in the framework of EPICA (European project for ice coring in Antarctica). Winckler and Fischer (2006) inferred a change in EDML dust provenance around $13000 \mathrm{yr} \mathrm{BP}$ from low resolution (30 samples over the past 30000 years) measurements of $\mathrm{He}$ isotopes. No continuous high resolution study exists for dust provenance during warm stages for the Atlantic sector of the EAP.

Using Rare Earth Elements (REE), this paper presents the highest resolution dust provenance study in the Atlantic sector of the EAP, covering the transition from the last glacial to the Holocene. This time interval is especially interesting, since it covers the large global glacial-interglacial temperature change $\left(5-6^{\circ} \mathrm{C}\right)$ accompanied by a dust flux decrease in Antarctica by a factor of 25 (e.g. Fischer et al., 2007).

REE are used as tracers for geochemical and cosmochemical processes. They are the elements lanthanum to lutetium with atomic numbers 57 to 71 , which are characterized by increasing electron occupation of the inner f-orbital and identical outer electron configuration. Thus, REE show (similar to isotopes) very similar chemical behavior, but exhibit small, although significant, differences in their incorporation in the crystal lattice caused by decreasing atomic radii with increasing atomic number (called lanthanide contraction). Additionally, REE show a rather conservative behavior in the environment caused by their low solubility and immobility in the terrestrial crust. Accordingly, REE compositions of aeolian dust show the corresponding fingerprints of their parental rocks in the source areas. Thus, comparing REE fingerprints of dust entrapped in the ice with those in PSAs represents a promising tool to identify provenances of dust. One advantage of REE compared to, for example, Sr and Nd isotopes, is that a 20 times smaller sample volume is required and little sample pre-treatment is necessary.

Gabrielli et al. (2006) successfully determined REE in EDC ice by inductively coupled plasma sector-field mass spectrometry (ICP-SFMS). This method offers the possibility to quantify REE concentration even at very low mass concentrations of dust, typical for ice from the Antarctic Plateau (12000 yr BP until today, dust concentrations: 10$15 \mathrm{ng} \mathrm{ml}^{-1}$; glacial, 26000-18000 yr BP, dust concentrations: $500-1000 \mathrm{ng} \mathrm{ml}^{-1}$; Lambert et al., 2008).

In a recent publication complementing this study, the dust provenance in the Indian Ocean Sector of the East Antarctic Plateau was already discussed by using REE as a dust proxy in the EDC ice core (Gabrielli et al., 2010). That study revealed a persistent crustal-like REE composition during the last glacial stage, which could be produced by one single source or a mix of several sources that together are well representative of the mean terrestrial contribution. At about $15000 \mathrm{yr} \mathrm{BP}$, a major change in REE composition was observed, which is explained by multiple single sources contributing individually to the much lower dust fallout to Dome C during the Holocene. A return to more glaciallike dust characteristics was observed between $\sim 8300$ and $7500 \mathrm{yr} \mathrm{BP}$, which was suggested to be due to the temporary reactivation of the glacial sources and the shutdown of others.

Here, we present a high resolution REE concentration record in the EDML ice core by using a set of 398 samples (each sample representing an ice section of $1 \mathrm{~m}$ length) covering the depth interval $493-1105 \mathrm{~m}$. This interval covers the transition from the LGS to the early Holocene $(26600 \mathrm{yr}$ BP to $7500 \mathrm{yr}$ BP; ages of ice core sections are from Ruth et al., 2007). Each sample represents a time interval of approximately 45 years at $26600 \mathrm{yr} \mathrm{BP}$ and approximately 20 years at $7500 \mathrm{yr}$ BP. In addition, we analyzed an extensive suite of samples from PSAs for REE in order to compare their REE fingerprint with that in the EDML ice and to assess the dust provenance.

With this approach, this study represents the first extensive study of dust provenance analysis based on REE in a deep ice core from the Atlantic sector of the Antarctic continent.

\section{Methods}

\subsection{Analysis of ice core samples}

After drilling, the EDML core was logged, packed in polyethylene bags and transported to the Alfred Wegner 
Institute (AWI) in Bremerhaven, Germany, where the ice was cut. A $32 \times 32 \mathrm{~mm}^{2}$ rod of ice from the inner part of the core was melted on a heated melthead, made of gold-plated copper for continuous high-resolution chemical analysis (Roethlisberger et al., 2000; Kaufmann et al., 2008). The melthead is divided into an inner section, where the innermost clean part of the ice and the outer section (where the ice is possibly contaminated) are separated. Only the clean innermost part of the ice was used for various trace analyses (for details see Roethlisberger et al., 2000 or Kaufmann et al., 2008), including REE measurements. Part of the meltwater from the inner part was collected in polystyrene (PS) beakers (Accuvettes) and immediately frozen. For the REE determination we followed the instrumental procedure described by Gabrielli et al. (2006) but with the following modifications: the slope of the calibration curve was determined using a set of matrix-matched multi-element standards obtained by melting a large surface snow sample taken from the area of the EDML drill site and spiked with different concentrations of a multi-REE stock solution (Perkin Elmer). Instrumental drift was checked using a $1 \mu \mathrm{g} \mathrm{l}^{-1}$ Indium (In) solution, analyzed at least after every 7 th sample. The maximum sensitivity was $3 \times 10^{6}$ counts s$^{-1} \mathrm{ppb}^{-1}$ In. The same isotopes as in Gabrielli et al. (2010) were used, except ${ }^{157} \mathrm{Gd}$ that was analyzed but not employed for data evaluation as mass 157 showed more elevated concentrations compared to ${ }^{158} \mathrm{Gd}$ and ${ }^{160} \mathrm{Gd}$, most likely due to interferences from ${ }^{141} \mathrm{Pr}^{16} \mathrm{O}$. In the presented study ${ }^{158} \mathrm{Gd}$ and ${ }^{160} \mathrm{Gd}$ were used, as no indication of residual interferences emerged. To check for the procedural blanks, 12 artificial ice cores made of ultrapure water (Millipore, resistance $>18 \mathrm{M} \Omega \mathrm{cm}$ ) were handled in the same way as the samples (Table 1). After subtracting this procedural blank, an unusual zig-zag shape showed up in the continental crust-normalized REE patterns (see below), whereas without blank subtraction the crust-normalized pattern showed the conventional smoothed form and anomalies only occurred for $\mathrm{Ce}, \mathrm{Eu}$ and $\mathrm{Tm}$. While $\mathrm{Ce}$ and $\mathrm{Eu}$ show well-known anomalies, this is not the case for Tm. Some studies report that Tm-concentrations in the UCC are not as well constrained as other REE, because of its mono-isotopic nature (e.g. Kamber et al., 2005). However, in this study an occurrence of an isotopic interference seems more likely as the Tm concentration given by Rudnick and Gao (2005) are consistent with Lu concentrations. For this reason, Tm is not included in the evaluation and discussion of the dust provenance. We argue that the REE concentration in the MQ water used to estimate the procedural blank did not originate from the sample processing but was linked to the production of the MQ water sample itself. One possibility is a contribution from the ion exchange columns for MQ water production. Another possibility is a contribution from the plastic bags that were used to freeze the MQ-water and produce the artificial ice core. The ice core samples were never in direct contact with the plastic bags, and thus are not affected by a possible blank contribution from the bags. For these reasons,
Table 1. Instrumental detection limit (LOD), mean Holocene (13 300-7500 yr BP) and glacial (26 500-16000 yr BP) REE concentrations in the EDML ice core and REE concentration in an artificial MQ ice core. Values are given in $\mathrm{pg} \cdot \mathrm{g}^{-1}$.

\begin{tabular}{lccrcc}
\hline & LOD & $\begin{array}{c}\text { Mean } \\
\text { Holocene }\end{array}$ & $\begin{array}{r}\text { Mean } \\
\text { Glacial }\end{array}$ & $\begin{array}{c}\text { Mean } \\
\text { Glacial/ } \\
\text { Mean } \\
\text { Holocene }\end{array}$ & $\begin{array}{c}\text { artificial } \\
\text { MQ-core }\end{array}$ \\
\hline $\mathrm{La}$ & 0.027 & 1.291 & 25.35 & 20 & 0.353 \\
$\mathrm{Ce}$ & 0.160 & 2.415 & 56.40 & 23 & 0.639 \\
$\mathrm{Pr}$ & 0.005 & 0.273 & 6.88 & 25 & 0.085 \\
$\mathrm{Nd}$ & 0.010 & 0.948 & 24.54 & 26 & 0.267 \\
$\mathrm{Sm}$ & 0.012 & 0.228 & 5.76 & 25 & 0.077 \\
$\mathrm{Eu}$ & 0.005 & 0.056 & 1.21 & 22 & 0.026 \\
$\mathrm{Gd}$ & 0.003 & 0.192 & 5.14 & 27 & 0.075 \\
$\mathrm{~Tb}$ & 0.002 & 0.030 & 0.75 & 25 & 0.019 \\
$\mathrm{Dy}$ & 0.002 & 0.157 & 4.11 & 26 & 0.044 \\
$\mathrm{Ho}$ & 0.001 & 0.032 & 0.78 & 24 & 0.009 \\
$\mathrm{Er}$ & 0.002 & 0.085 & 2.07 & 24 & 0.024 \\
$\mathrm{Tm}$ & 0.001 & 0.014 & 0.29 & 20 & 0.006 \\
$\mathrm{Yb}$ & 0.002 & 0.075 & 1.74 & 23 & 0.029 \\
$\mathrm{Lu}$ & 0.002 & 0.013 & 0.25 & 20 & 0.010 \\
\hline
\end{tabular}

we decided not to subtract the presumed procedural blank from the sample concentrations.

All samples with a concentration below the detection limit (LOD) were discarded. LOD was calculated as 3 times the standard deviation of the analytical blank, determined from ultrapure water (ELGA Labwater) produced at the University of Venice and analyzed every 7th sample. To check for reproducibility, duplicate sample measurements were performed regularly. A total of 72 samples, randomly chosen, over the whole record were analyzed twice, 9 samples three times and one sample 4 times. Additionally, a sample from recent firn from the area of the EDML drill site was measured regularly (a total of 16 times) during the analytical sessions. The mean reproducibility of REE varied consistently between $13 \%$ and $26 \%$ for the firn and between $19 \%$ and $31 \%$ for the randomly chosen samples. This range of uncertainty is also valid for replicate analysis of low concentration Holocene samples and provides the overall uncertainty of the determinations. The typical values for LOD are given in Table 1. Additionally, the mean concentrations during warm (13 300-7500 yr BP) and cold climates (26500$16000 \mathrm{yr}$ BP) are given. The glacial concentrations are, depending on the element, one to two orders of magnitude above the LOD. Also, the concentrations recorded during the Holocene are still well above the LOD. Differences in the recovery of REE determination in samples treated with procedures were carefully investigated in EDC ice (Gabrielli et al., 2010), yielding about $40-60 \%$ of recovery for samples treated with a simple slight acidification compared to a 
full-acid digestion, with slightly lower recoveries for heavier REE. The dust deposited in EDC and Vostok ice consists mainly of clays (mostly illite) during glacial times, while during the Holocene dust shows a higher degree of weathering (Gaudichet et al., 1986, 1988). For EDML, no studies on the mineralogy are available so far, but, due to the similar chemical composition (Marino et al., 2009), the results from Gabrielli et al. (2010) can be taken into account also when discussing REE determination in EDML ice. As extensively shown in Gabrielli et al. (2010), the major changes in REE composition occurring during the glacial-Holocene transition are not sensitive to the identified differences in the REE recovery. Nevertheless, when discussing changes in the dust provenance by comparison with samples from the PSAs, these different recoveries have to be kept in mind.

\subsection{Analysis of samples from the potential source areas (PSAs)}

A total of 33 samples from PSAs were analyzed to determine their REE patterns. An overview of the sampling locations is given in Fig. 1 and more information about these samples is given in the Supplement. Data for part of these samples were already presented in Gabrielli et al. (2010). The dust samples collected from the PSAs span a wide size spectrum differing from sample to sample. For this analysis, only the $<5 \mu \mathrm{m}$ fraction was used. This corresponds to the typical size of the particles found in Antarctic ice cores (e.g. Delmonte et al., 2004a). As described by Delmonte (2003), the bulk of the sample (a few grams) was suspended in $45-50 \mathrm{ml}$ of ultra pure water. After $10 \mathrm{~min}$ of ultrasonication, the sample was left to separate by settling according to Stokes law. The supernatant was taken up with a pipette and the size distribution was checked to achieve a fraction of $95 \%$ of the total mass of particles in a size range $<5 \mu \mathrm{m}$. The supernatant was treated with a full acid digestion in high pressure PFA beakers using $\mathrm{H}_{2} \mathrm{O}_{2}$ (suprapure, Fa. SCP Science), HF (subboiled, $40 \%$, suprapure, Merck) and $\mathrm{HNO}_{3}$ (subboiled, $65 \%$, pro analysis, Merck) to dissolve the sample matrix. The digestion and the analysis of the samples were performed under a clean bench (US Standard, Class 100) in the clean room facilities at AWI. To each sample, $10 \mu \mathrm{g} \mathrm{l}^{-1} \mathrm{Rh}$ was added to provide an internal standard to correct for instrumental drift during the analysis. Blanks were prepared using ultrapure water, treated in the same manner as the dust samples and analyzed at least after every 7th sample. For PSA samples, as opposed to the ice core samples, the median of the blank values was subtracted from the sample concentration. The median was chosen, as a few outliers dominated the mean value. The blank values were less than $0.5 \%$ of the mean concentration and less than $10 \%$ of the lowest PSA sample concentration level. However, blank subtraction did not change the pattern considerably. Calibration standards were prepared from multi-element stock solutions (Multielement Calibration Standard 2 and 3, Perkin-Elmer). These analyses

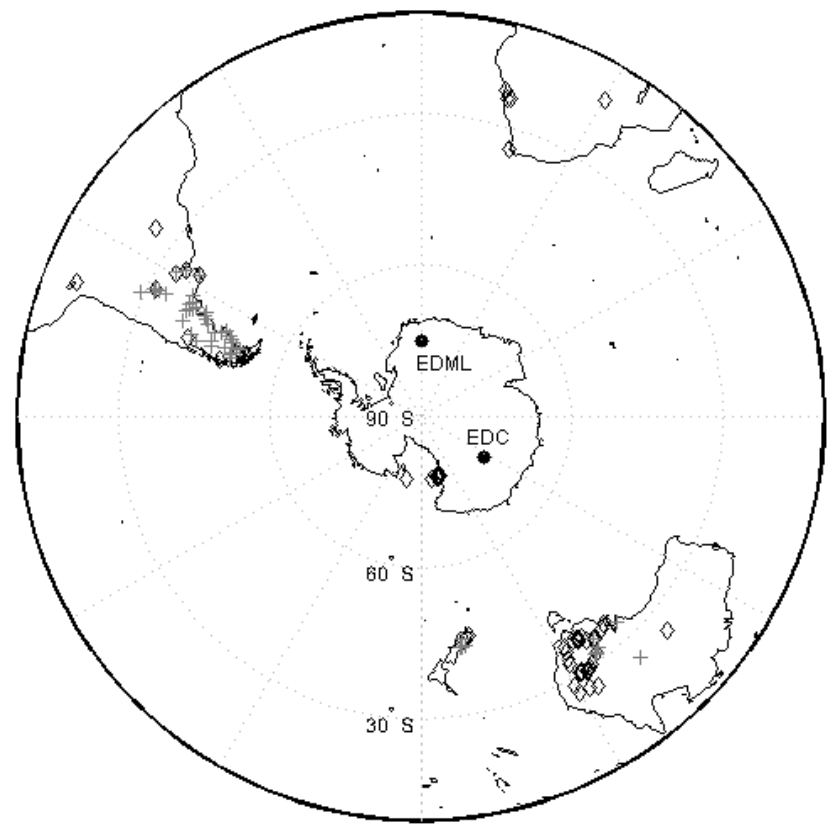

Fig. 1. Map of sample locations. Diamonds indicate samples from this study, crosses represent previously published data (see text for references). EDML and EDC indicate the drill sites for the two deep ice cores drilled within the framework of EPICA in Dronning Maud Land and at Dome C.

were performed at AWI by ICP-QMS (ELAN 6000, Perkin Elmer/Sciex 1997) coupled to a micro concentric nebulizer made of PFA placed in a heated PFA spray chamber followed by a heated membrane desolvation unit MCN-6000 (Cetac). Here, the solvent was removed with a counter flow gas and oxide formation minimized $(\mathrm{CeO} / \mathrm{Ce}$ was $0.02 \%$ when compared to $3 \%$ of a conventional spray chamber). The sample uptake was $100 \mu \mathrm{min}^{-1}$. The mean sensitivity obtained during the analysis was $5 \times 10^{5}$ counts s${ }^{-1} \mathrm{ppb}^{-1} \mathrm{Rh}$, with a variation between two calibrations of $20 \%$ or less. For correction of the instrumental drift, a spike of $10 \mu \mathrm{g} \mathrm{l}^{-1} \mathrm{Rh}$ as an internal standard was used. More detailed information about instrumental conditions and analysis settings are given in the Supplement and a direct comparison of identical samples in both labs in Venice and at AWI is given by Dick et al. (2008).

\section{Results}

\subsection{Ice core samples}

As an example for the REE concentration, the La concentration across the last glacial-interglacial transition is shown in Fig. 2 together with the typical (soluble) dust proxy non sea salt (nss) $\mathrm{Ca}^{2+}$ (Fischer et al., 2007) and the corresponding temperature changes as represented by $\delta^{18} \mathrm{O}$ (EPICA, 2006). $\mathrm{La}$ concentrations are higher by a factor of 20 during the LGS (26 500-16000 yr BP) compared to the early Holocene 


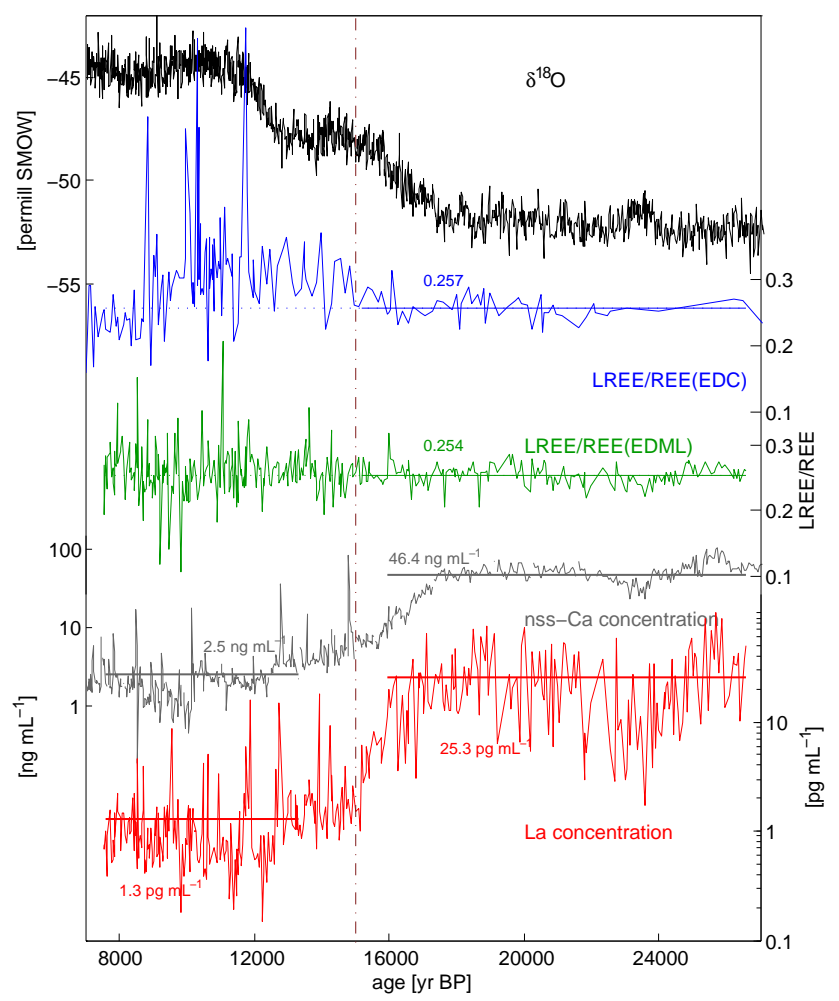

Fig. 2. Different proxies in the EDML and EDC ice cores over the LGS to Holocene transition: $\delta^{18} \mathrm{O}$ isotopic composition (top panel, EPICA, 2006); LREE/REE ratios clearly show a constant value at 0.254 during the LGS and Holocene changing to more variable ratios at $15000 \mathrm{yr} \mathrm{BP}$ as indicated by the dashed vertical line. The corresponding LREE/REE profile from EDC also shows a change around $15000 \mathrm{yr} \mathrm{BP}$. nssCa ${ }^{2+}$ concentration is a proxy for dust concentrations (after Fischer et al., 2007); La concentration is a proxy for REE concentrations.

(13 300-7500 yr BP). Typically, the LGS/Holocene ratios for the other REE are in the range of 20-27 (see Table 1, together with the mean Holocene and LGS REE concentrations). The LGS/Holocene REE ratios are slightly higher than those for $\mathrm{nssCa}^{2+}$ concentrations (19) determined by ion chromatography (IC, Fig. 2, Fischer et al., 2007), which can partly be explained by the fact that $\mathrm{Ca}^{2+}$ concentrations in Holocene ice are close to the detection limit of the IC $\mathrm{Ca}^{2+}$ measurements and can be taken as an upper limit for the mean concentration.

The systematic shape of the REE patterns for individual samples was investigated. To this end, all samples were normalized to the typical upper continental crust value (Eq. 1 is an example for $\mathrm{La}$ ):

$\mathrm{La}^{*}=\frac{\mathrm{La}_{\text {ice }}}{\mathrm{LaUCC}}$

with $\mathrm{La}_{\text {ice }}$ being the La concentration in the ice sample, and LaUCC the typical La concentration in the upper continental crust (UCC, Rudnick and Gao, 2005). Although REE concentration in samples from glacial and interglacial periods differ significantly due to the much higher dust input to Antarctica during glacial times, a source change would affect the shape of the REE fingerprint, independent of the absolute concentration. For a better comparison of the shape of the patterns, a second normalization step was applied to eliminate the effect of the concentration values on the absolute values of the ratios (Eq. 2):

$\mathrm{La}_{\text {norm }}=\frac{\mathrm{La}^{*}}{\overline{\mathrm{REE}^{*}}}$

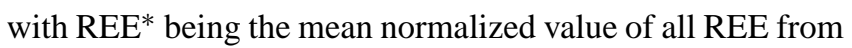
Eq. (1). Figure 3a shows the mean REE pattern between $26600 \mathrm{yr} \mathrm{BP}$ and $15000 \mathrm{yr} \mathrm{BP}$. This pattern is very uniform and shows a mean enrichment of $\sim 17 \%$ in MREE ( $\mathrm{Sm}, \mathrm{Eu}$, $\mathrm{Tb}$, Dy) and a mean depletion of $\sim 11 \%$ in LREE (La, Ce, Pr, $\mathrm{Nd}$ ) relative to the mean REE concentration and a depletion of $\sim 8 \%$ in HREE (Ho, Er, Yb, Lu). After $\sim 15000 \mathrm{yr} \mathrm{BP}$, the pattern becomes more heterogeneous (Fig. 3b). This shift coincides with the slowdown of the warming trend, which at $\sim 14500 \mathrm{yr}$ BP turns into the Antarctic Cold Reversal (ACR, Blunier et al., 1997). The EDML pattern shows a very similar shape compared to the EDC pattern $(r=0.98)$ during the glacial time interval (26600 yr BP-15 $200 \mathrm{yr} \mathrm{BP}$ ), independently supporting the findings of Marino et al. (2009) pointing out a similar mineral composition at these two sites. During the Holocene, the patterns at both sites differ more than during the glacial $(r=0.20)$; however, for each of the REE the normalized values at EDC and EDML lie well within their error limits for these low concentration interglacial samples

The thickest visible ash layer of the whole EDML ice core occurs at $808.2-808.3 \mathrm{~m}$ depth $(\sim 14800 \mathrm{yr} \mathrm{BP})$. This ash layer dominates the REE pattern of sample 809 (Fig. 3c), which shows a strong enrichment of $45 \%$ in HREE and which is also accompanied by a 3-4 times higher sulphate concentration compared to the background value. The REE pattern of this ice section is not representative of aeolian dust but essentially reflects the REE composition of tephra emitted during an eruption or a set of eruptions.

During the Holocene, different patterns occur in individual samples. They are shown in Fig. 4 grouped by the similarity of their pattern. The patterns are defined as follows: glacial-type (93 samples) samples recorded during the Holocene, which do not deviate from the glacial mean more than 0.015 in the sum of the squared differences of each REE from the glacial mean; A-type (21 samples), characterized by a positive Ce-anomaly $>1.2$; B-type ( 15 samples), characterized by HREE/REE $\leq \sim 0.4$; C-type ( 24 samples), characterized by a positive Eu-anomaly $>1.7$; D-type ( 2 samples) LREE/REE > 1.3; and E-type (80 samples): samples, that cannot be classified to any other category (not shown in Fig. 4). Most of these E-type samples were similar to the glacial type, but are more enriched in Sm and Eu. Figure 5 shows the occurrence of all these different patterns over 

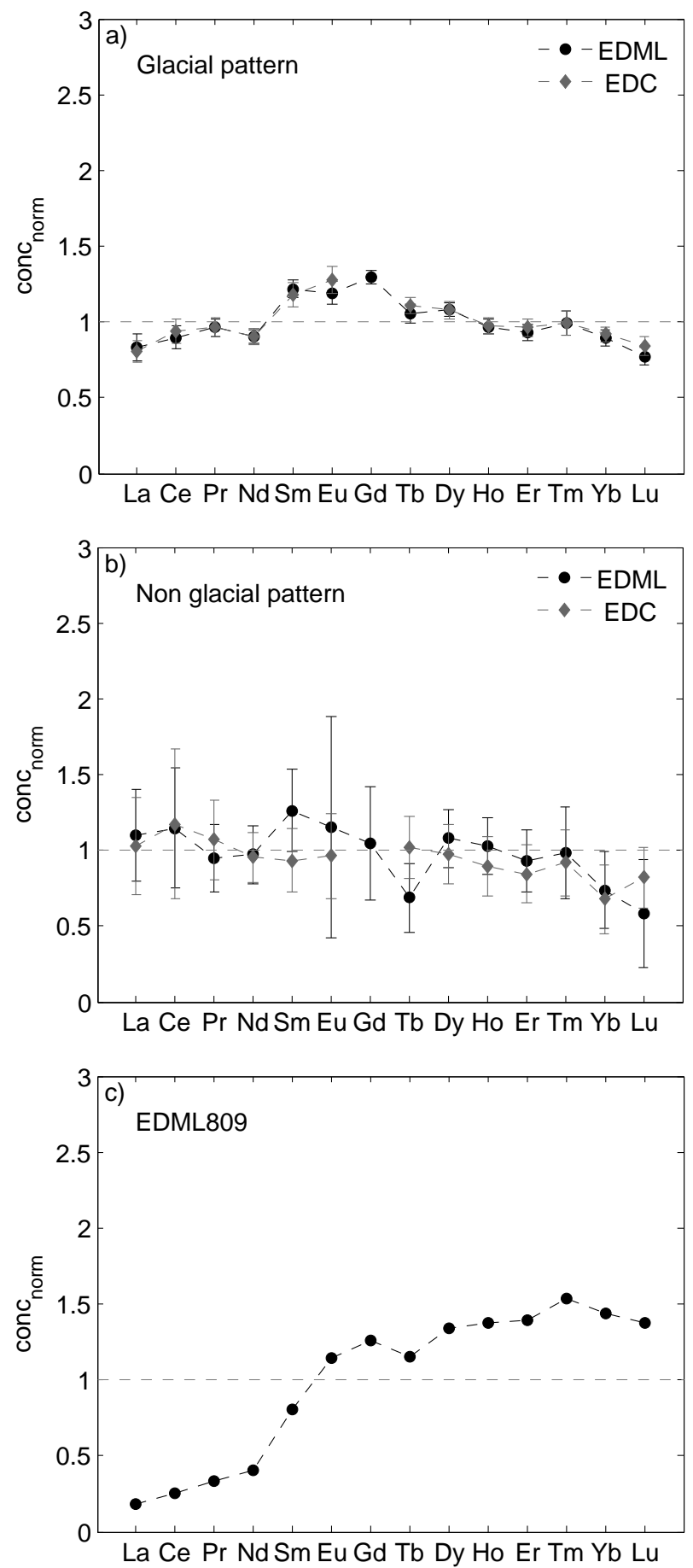

Fig. 3. Mean REE pattern from 27000 to $15200 \mathrm{yr} B P$ (a) and 15200 to $7500 \mathrm{yr} \mathrm{BP}$ (b). Error bars indicate the $1 \sigma$ standard deviation of the variability for each REE. Much higher sample heterogeneity is clearly identifiable during the Holocene compared with the LGS and early transition, which is, in part, due to the low concentrations. The graph (c) displays a pattern with a strong enrichment in HREE, from the depth interval containing the thickest volcanic ash layer in the whole EDML ice core. time. Before $15000 \mathrm{yr} \mathrm{BP}$, only one sample does not show the glacial pattern. Between 15000 and $13000 \mathrm{yr}$ BP, about half of the samples are characterized by the glacial pattern, while between 7000 and $13000 \mathrm{yr}$ BP, only about one third of the samples still show the glacial pattern.

\subsection{Samples from the potential source areas}

The locations of the sampling sites, where the 33 samples from PSAs were collected, are shown in Fig. 1 and more information about the samples is given in the Supplement and in Delmonte et al. (2004b). The samples do not provide a complete set of all dust areas, but represent spotlights that provide a picture from where dust may originate. Figure 6 shows the corresponding patterns, sorted by continent and normalized according to Eq. (2). All PSAs show different features: the samples from the ice free areas on the Antarctic continent (mainly from the Dry Valleys) are characterized by a variable Eu-anomaly (0.9-1.5, one exception 0.3$)$ and slightly enriched LREE ( $21 \%)$, while the African samples show a $\sim 20 \%$ MREE enrichment. The samples from Australia mostly originate from the south-eastern part of the continent. These samples are characterized by a LREE depletion of $\sim 8.5 \%$. In the Australian samples, some HREE could not be evaluated; in these cases, the evaluated REE were used for interpolation of the missing REE. This has to be kept to when discussing the HREE in these samples. On average, the samples from New Zealand exhibit a similar depletion in LREE $(\sim 6.5 \%)$ accompanied by an additional enrichment in MREE of up to $35 \%$ for some samples. Most of the samples used in this work were collected in South America. These samples are characterized by a depletion in LREE ( $20 \%)$ and a small enrichment in MREE $(\sim 5 \%)$ as well as HREE $(\sim 11 \%)$. Other South American data from the literature are also used for our discussion (Gaiero et al., 2004; Smith et al., 2003). A drawback of the latter data is that the analyses were performed on bulk samples, whereas we only used the $<5 \mu \mathrm{m}$ fraction. In Fig. 7, the REE compositions of the samples from different PSAs are displayed.

The different PSAs cannot be separated completely. The South American samples and the Australian samples show a considerable overlap with the samples slightly enriched in HREE. Note that for most Australian samples, the complete HREE spectrum could not be evaluated; thus, the enrichment in HREE is based on fewer elements than for the other PSAs. For South American PSAs, the size-fractionated samples analyzed for this study were more enriched in MREE, indicating a size-dependant effect for the analysis. As mentioned earlier, dust in ice cores from East Antarctica mainly consists of clays, which are depleted in REE compared to quartz or other major silicates (Henderson, 1984); thus, the REE content in ice core dust is better preserved than in other minerals, but biased to smaller dust sizes in the PSA. There are also PSAs that can be clearly separated from each other (Fig. 7); for example, the ice-free areas in Antarctica show 

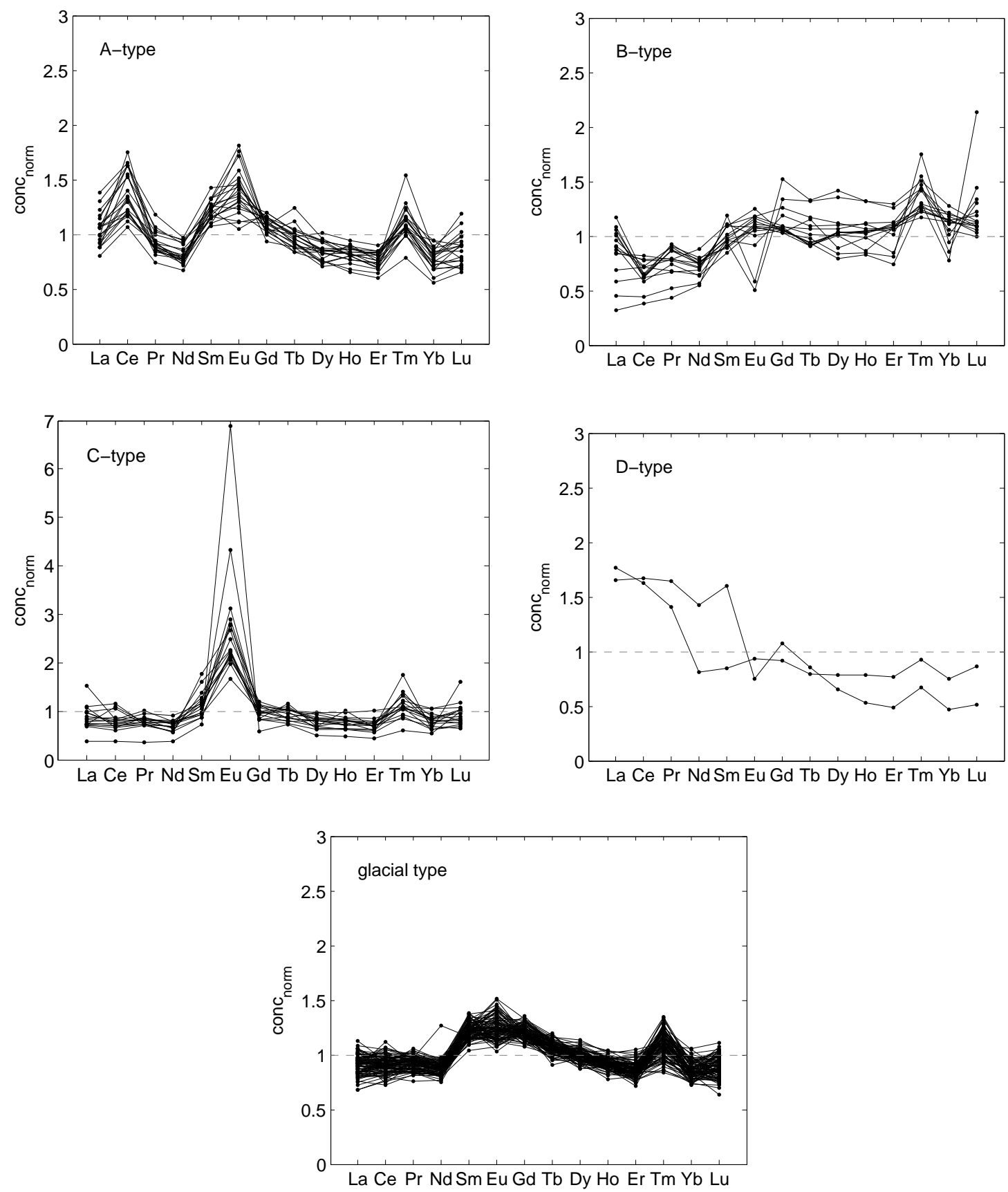

Fig. 4. Typical Holocene REE patterns. The characteristic variations in the Eu-anomaly and the HREE/LREE ratios are clearly identified. See text for the characterisation of the different REE types.

a distinct enrichment in LREE. Only a limited number of Antarctic samples have been collected, so for a conclusive interpretation of the EDML dust, samples from the mountain ranges of DML would be beneficial. We conclude that it is not possible to exclusively allocate the ice core samples to an individual PSA but REE offers a fast and highly resolved means of first-order provenance analysis.

\section{Discussion of the dust provenance}

\subsection{Last glacial stage and the transition to the Holocene}

The REE patterns in the EDML ice core are very consistent throughout the LGS until $\sim 15000 \mathrm{yr} \mathrm{BP}$, pointing toward one dominant source (or a constant mix of different sources) during this time period in accordance with the findings of Gabrielli et al. (2010). Indeed, comparing REE from 


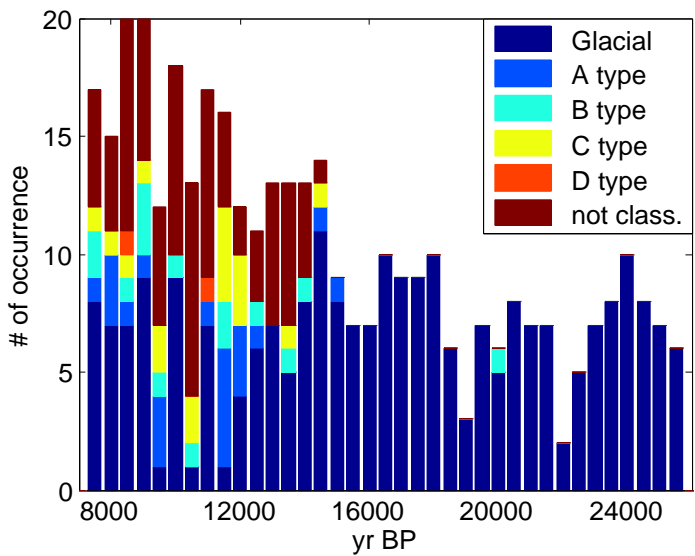

Fig. 5. Histogram of the different REE patterns over time: the majority of the samples before $15000 \mathrm{yr} \mathrm{BP}$ are classified as belonging to the glacial pattern. During the glacial fewer samples were measured.

EDML with those from EDC (Fig. 3), they exhibit the same pattern. Considering the different distances of EDML and EDC to the various potential circum-Antarctic dust sources the very good correspondence of the glacial REE pattern for both cores points to one dominant source region controlling both ice core sites. In both ice cores, patterns start to change at approximately the same time $(\sim 15000 \mathrm{yr} \mathrm{BP})$, indicating a common and stable dust input during the LGS and the first part of the transition. This simultaneous change in EDML and EDC at $\sim 15000 \mathrm{yr} \mathrm{BP}$ is obvious also from the LREE/REE ratio (Fig. 2). Winckler and Fischer (2006) observed a change in dust provenance $\sim 13000 \mathrm{yr} \mathrm{BP}$, slightly later than we do, but with a much coarser sampling resolution that did not allow them to pinpoint a clear point in time for the dust provenance change. During the LGS and until around $15000 \mathrm{yr} \mathrm{BP}$, the LREE/REE ratio remains rather constant around 0.25 both in EDML (0.254) and EDC (0.257). The slight age difference can be explained by the different sampling resolution. Again, the very good agreement of the LREE/REE ratio in both cores points to one dominant dust source for both regions of the EAP. From around $15000 \mathrm{yr}$ until $7500 \mathrm{BP}$, LREE/REE in EDML exhibits higher variability, while EDC shows a distinct augmentation pointing to input of dusts from distinctly different sources for these two sites during the Holocene.

When comparing the REE determined in ice with those in the PSA samples, the aforementioned differences in analytical REE recoveries have to be kept in mind. The glacial pattern is characterized by enrichment in MREE relative to the mean REE and by a slight enrichment in HREE compared to LREE. This is similar to the pattern observed for the samples from the South American PSAs. In Fig. 8, the correlation coefficients $R$ of the glacial REE patterns versus the mean pattern of each PSA are plotted. $R$ is an indicator for the similarity of the patterns. The highest correlation of the glacial pattern is achieved with those samples collected in South American, Australian and African PSAs. The differentiation between South America, Southern Africa and Australia (showing a higher similarity with the glacial pattern) from Antarctica and New Zealand is obvious. Based on this analysis, Antarctica and New Zealand PSAs do not seem to play a major role during the LGS dust input to DML. This finding supports the conclusion by Marino et al. (2009) that during the LGS the main dust input to DML originated from South America.

To further distinguish between the different PSAs during the LGS, Fig. 7 shows the relative contribution of LREE, MREE and HREE to REE. This graph includes previously published REE values (Smith et al., 2003; Marx et al., 2005; Gaiero et al., 2004). The glacial samples (grey dots) form a tightly-defined field which is located in the South American and African fields and outside the Australian and the Antarctic fields. Southeastern Australia and Antarctica may be therefore excluded as a major PSA for DML during the LGS. However, the Australian field is not as well constrained as the other fields due to gaps in the pattern of several samples. The plot in Fig. 7 shows also that southern Africa might have contributed as a dust source to DML during glacial times. However, as EDML is located at $0^{\circ} \mathrm{E}$ and the west coast of southern Africa runs at a longitude between $10^{\circ}$ and $20^{\circ} \mathrm{E}$, the prevailing westerly winds should prevent the transport of large air masses from South Africa to the East and thus to DML. Taking into account the slightly different recoveries for the PSAs compared to ice samples, the higher recovery of HREE in ice would suggest that there is a bias in the location of the glacial samples, such that they may overlap with the fields of South American and Australian PSAs. Thus, we cannot completely exclude Australia as a source during the LGS.

Since most of the PSA samples originate from South America, we also attempt a distinction in subregions (Fig. 9). With increasing latitude, we find a tendency for the samples to be more enriched in HREE and MREE. However, this trend is not pronounced enough to distinguish between distinct sources in South America. Studies employing Sr and $\mathrm{Nd}$ isotopic fingerprinting have been performed by Gaiero (2007), which may permit a discrimination between different source areas in southern South America. A comparison of $\mathrm{Sr}$ and $\mathrm{Nd}$ isotope data from other Antarctic ice cores, including EPICA Dome C, Talos Dome, Dome B, Vostok and Komsomolskaya, displays a common Patagonian source, calculated to account for $70-100 \%$ of the dust delivered to the East Antarctic Plateau between $90^{\circ} \mathrm{E}$ and $180^{\circ} \mathrm{E}$ during glacial times (Delmonte et al., 2008). REE data presented here support this overall scenario, with much greater temporal detail for much less analytical effort. This study shows a constant source or mix of sources, most likely located on the South American continent, providing the LGS dust deposited at DML. The transport of dust from southern South America is also favourable because DML is located closer 

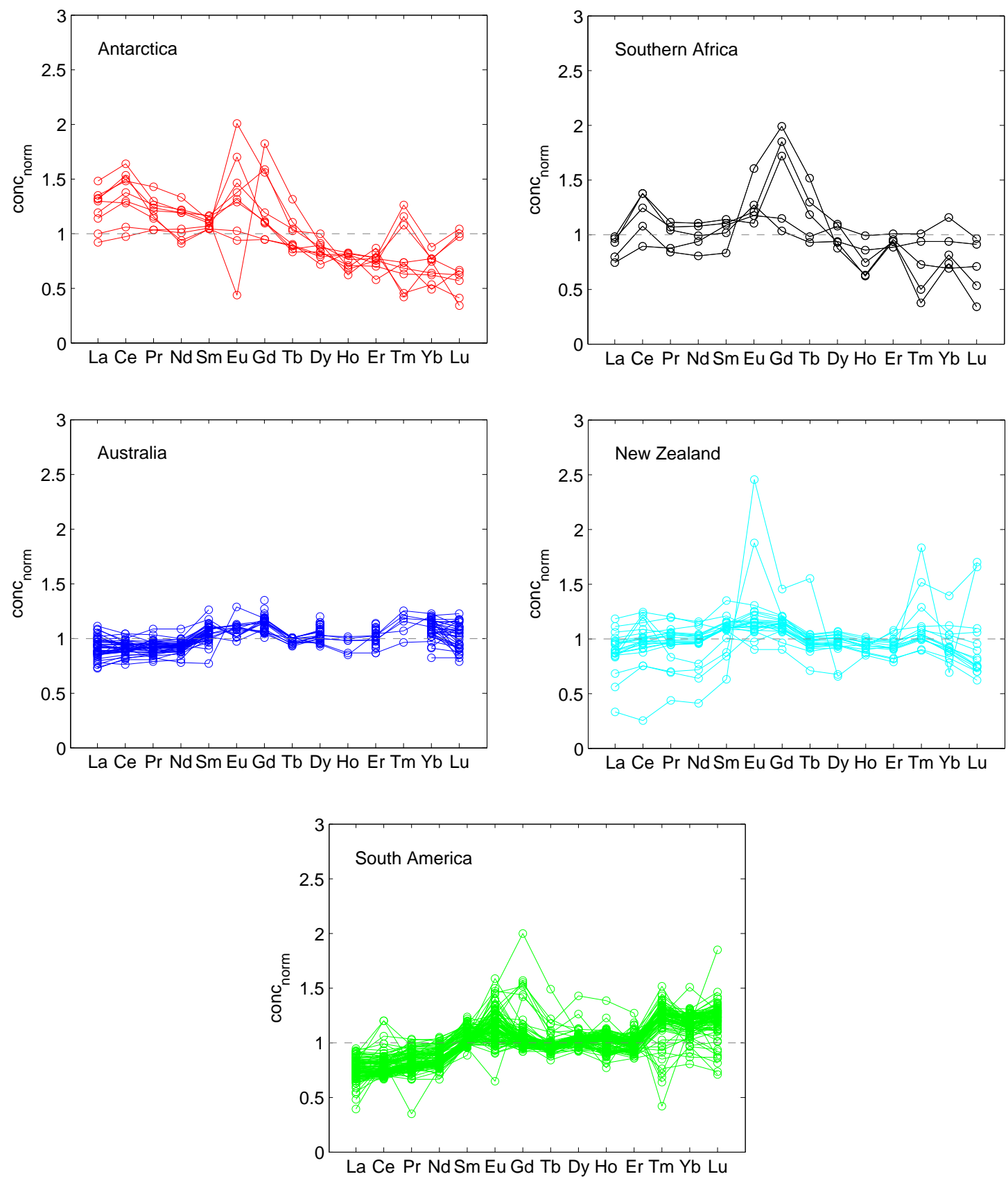

Fig. 6. REE patterns in the samples from the PSAs.

to Patagonia than the other ice cores drilled on the Antarctic Plateau and lies within the main pathways of air masses transported over the Atlantic sector of the Antarctic Plateau (Reijmer et al., 2002).

\subsection{Late transition and early Holocene (15200 to 7500 yr BP)}

The Holocene REE patterns are different and more variable compared to those of the glacial, likely due to greater variety of dust sources. Figure 2 shows the LREE/REE ratio calculated for the EDML and EDC ice cores. As mentioned above, a significant change in the variability at $\sim 15000 \mathrm{yr} \mathrm{BP}$ is observed (Fig. 3). The EDML record does not show a return to glacial values as observed in the EDC record in the early Holocene between $\sim 7500$ and $\sim 8300 \mathrm{yr}$ BP. Thus, the dust cannot originate from the same sources at that time and perhaps during the early part of the Holocene as shown by the different LREE/REE ratios in EDC and EDML. 

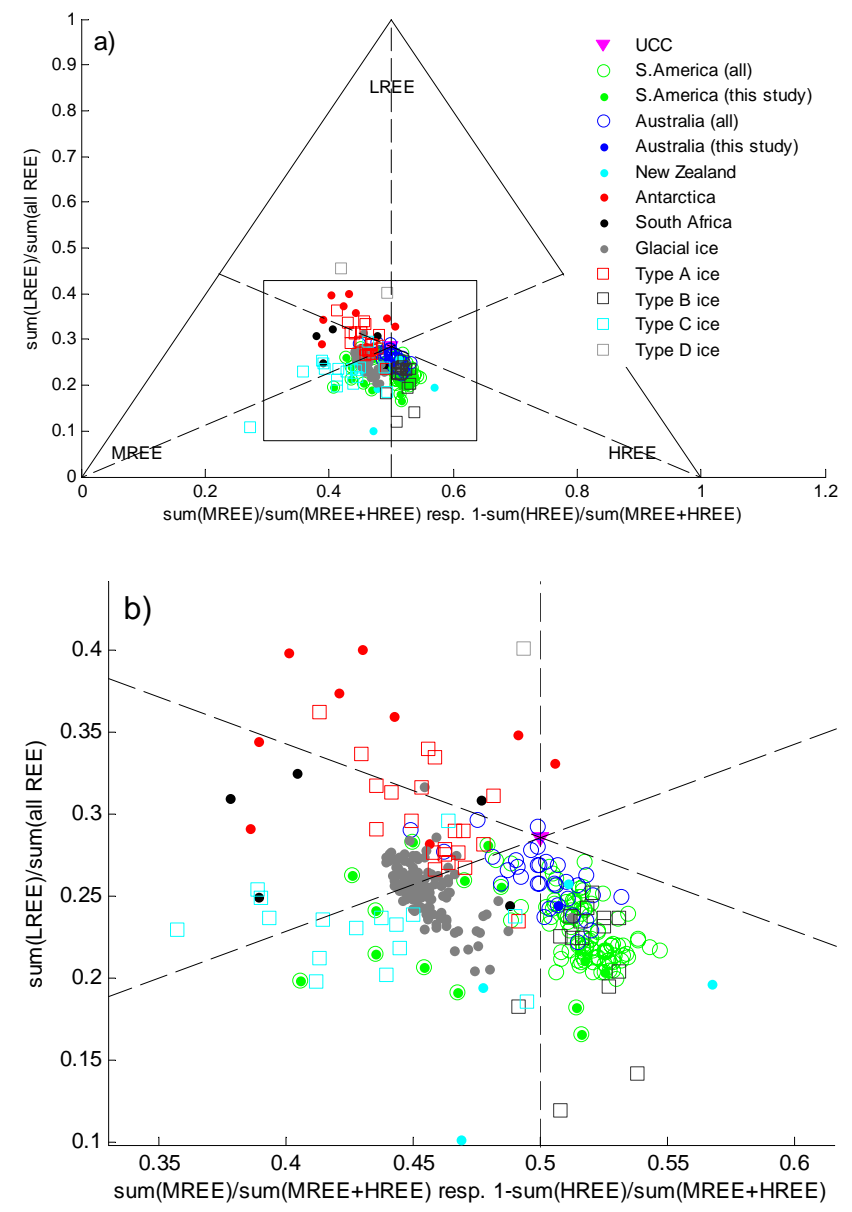

Fig. 7. Plot of the ratios of LREE, MREE and HREE of crustnormalized concentrations. The PSA samples are indicated as follows: South America: green dots, southeastern Australia: blue dots (for Australia and South America, the samples for this study $(<5 \mu \mathrm{m})$ are indicated with circles around the dots), Antarctica: red dots, southern Africa: black dots, New Zealand: light blue dots. Glacial EDML samples are indicated with grey dots. All other ice core samples are represented by squares: Type A red, Type B dark grey, Type $\mathrm{C}$ light blue, Type D light grey. See Fig. 3 and the text for a description of the different types. The crossing point of the dashed lines indicates the normalized UCC composition (magenta triangle). The glacial samples are clearly located in the area covered by the South American samples: (a) complete overview, (b) zoom of the central box.

We now discuss the possible contributions of the multiple PSA to DML ice for the late transition and the Holocene. The majority of the samples (97 out of 224) show a typical glacial signature (Fig. 6), indicating an important contribution (40$50 \%$ ) from South America also during the Holocene, albeit at a lower level. The reduced South American input during the Holocene may permit detection of the REE signature of dust from other sources. Type B (Fig. 4) is characterized by an enrichment in HREE and occurs 15 times during the Holocene. This same pattern is observed in Australian PSA

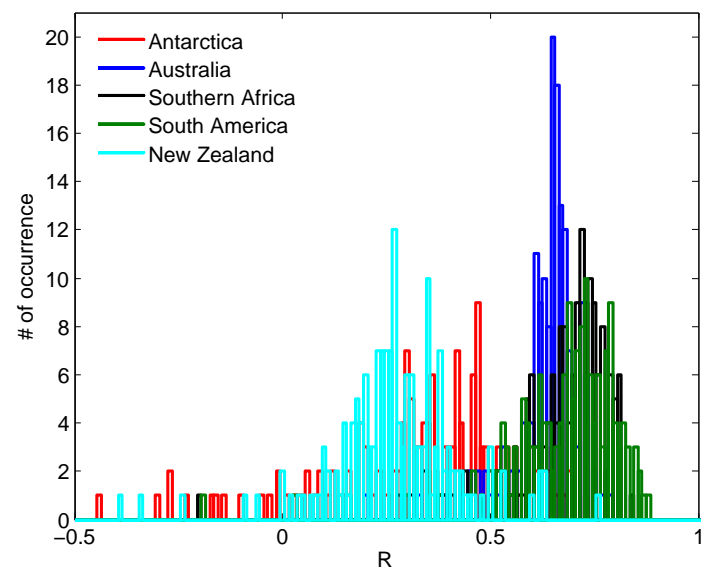

Fig. 8. Histogram of the correlation coefficient $R$ of the REE pattern of each sample between 26500 and $15200 \mathrm{yr}$ BP and the mean REE pattern of each PSA (red: exposed areas in Antarctica, green: South America, blue: south eastern Australia, black: southern Africa, light blue: New Zealand). Each ice sample from the glacial stage was correlated with the mean value from each PSA. Thus, for each PSA 165 values for $R$ were calculated, which are plotted here. For this calculation the crust-normalized values were used according to Eq. (2).

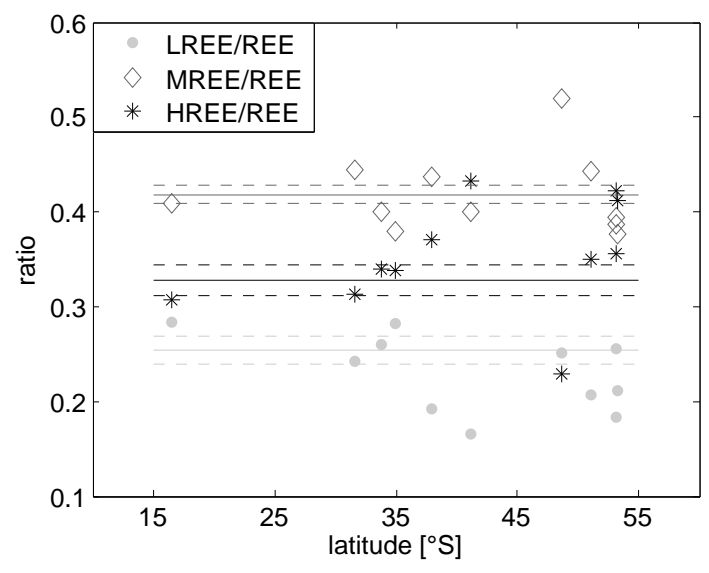

Fig. 9. Ratios between light, medium and heavy REE with latitude in South America: Horizontal lines give the mean glacial values with $1 \sigma$ standard deviation (dashed line) (upper line MREE/REE, middle line HREE/REE and bottom line LREE/REE.

as well as in the tephra pattern found at 809 to $808 \mathrm{~m}$ depth. Since none of these ice core samples are accompanied by a significantly elevated sulfate concentration, we conclude that these samples likely reflect a detectable dust input from southeastern Australia. Type A samples with a pronounced Ce-anomaly and type D samples with a strong enrichment in LREE similar to the pattern of the Antarctic PSA samples (Fig. 6) occur 23 times in total. During the Holocene, Antarctic PSA have likely been more active compared to before $\sim 15000$ yr BP. Pattern Type C (Fig. 4) is characterized by an 
enhancement in Eu, which can only be found in the PSA samples from New Zealand, therefore indicating this area may have occasionally contributed to Holocene dust inputs.

Of particular interest is the distinct onset of contributions from multiple sources at $\sim 15000 \mathrm{yr}$ BP. The atmospheric dust concentration, expressed by the nssCa flux, reached $28 \mathrm{ng} \mathrm{cm}^{2} \mathrm{yr}^{-1}$ at that time, which is only about $60 \%$ higher than the mean nssCa flux during the Holocene $\left(17 \pm 18 \mathrm{ng} \mathrm{cm}^{2} \mathrm{yr}^{-1}\right.$, Fischer et al., 2007). Thus, at $15000 \mathrm{yr}$ BP the atmospheric dust concentration reaching Dronning Maud Land decreased to almost Holocene levels without any significant change in the dust provenance. At that time, the temperature was still halfway between glacial and Holocene levels (Fig. 2). Around 15000 yr BP, a marked change in the dust composition was already observed in the EDC ice core (Siggaard-Andersen et al., 2007; Gabrielli et al., 2010). Both EDML and EDC ice cores are synchronized by matching records of volcanic signals (Severi et al., 2007) and thus, significant differences in the timescales can be excluded. We conclude that, starting at $15000 \mathrm{yr} \mathrm{BP}$, dust from other sources can be detected over the East Antarctic Plateau. Around $19000 \mathrm{yr} \mathrm{BP}$, the onset of deglacial warming was observed at the northern margin of the Antarctic Circumpolar Current, potentially accompanied by a southward shift of the southern westerly wind belt (Lamy et al., 2004). This coincides with the onset of the dust concentration decrease in EDML, indicating that the southward shift of the westerly wind belt contributed to changed conditions such as vegetation cover and precipitation in South America. This may have resulted in a weakening of the emissivity or a decreasing size of the dust source areas in South America. Additionally, Sudgen et al. (2009) observed a weakening of the South American dust source, starting from $15000 \mathrm{yr} \mathrm{BP}$, due to glaciers terminating into proglacial lakes instead of vast outwash plains.

The decrease in dust input to the East Antarctic Plateau before $15000 \mathrm{yr}$ BP can be explained by a weakening of the emissivity of the PSA caused by increased vegetation cover or a change in local precipitation (wetter conditions). After $\sim 15000 \mathrm{yr}$ BP, dust emissions from South America substantially declined and dust from other sources can be identified in Antarctica, indicating a reorganization of the atmospheric circulation such as a southward shift of the westerly wind belt (Lamy et al., 2004). This is supported by earlier studies at EDC (Gabrielli et al., 2010; Siggaard-Andersen et al., 2007; Roethlisberger et al., 2002) but for the first time is observed here in the Atlantic sector of the Antarctic Plateau. Whether other PSAs also had an influence on dust composition in Antarctica during glacial times cannot be assessed within this study due to the dominating glacial dust input from South America.

\section{Conclusions}

In this study, we investigated the REE composition in EDML ice over the last climatic transition spanning the period $26500-7500$ yr BP. REE fingerprints in ice core dust samples can help identify potential source areas, even if the separation of individual source fields is not unambiguous for all PSAs. The main advantages of REE studies with respect to traditional $\mathrm{Sr}$ and $\mathrm{Nd}$ isotope studies are the much higher temporal detail, greater analytical ease and the small sample size required. During the LGS and up until $\sim 15000 \mathrm{yr} B$, the REE dust composition is uniform and reveals a constant source or a constant mix of sources. REEs in the ice core samples are similar to those determined in dust samples collected from South American PSAs. From $\sim 15000 \mathrm{yr}$ BP, REEs from other source areas, such as the southeastern part of the Australian continent, can be recognized but for about $40-50 \%$ of the ice samples the dust reaching Dronning Maud Land still resembles the glacial pattern. A concurrent change in REE composition at Dome $\mathrm{C}$ at $\sim 15000 \mathrm{yr} \mathrm{BP}$ suggests a synchronous change of source areas for the entire East Antarctic Plateau, although in EDML ice the main dust provenance is still the same as during the LGS in line with the downwind position of DML relative to the South American dust sources. Similarly, when a return to glacial dust characteristics was observed at Dome $\mathrm{C}$ between $\sim 8300$ and $\sim 7500 \mathrm{yr}$ BP, REE patterns appear to be unchanged in DML. This, together with a distinct LREE/REE ratio, points to different dust contributions to DML and Dome $\mathrm{C}$ during the Holocene. A weakening of the glacial sources during the first part of the transition and a reorganization of the atmospheric circulation enabled the detection of dust from other PSAs in DML during the early Holocene. At that time, contributions of southeast Australian dust seem to have been significant, but also dust inputs from New Zealand and Antarctic sources may have occurred.

\section{Supplementary material related to this article is available online at: http://www.clim-past.net/8/135/2012/ cp-8-135-2012-supplement.pdf.}

Acknowledgements. This work is a contribution to the European Project for Ice Coring in Antarctica (EPICA), a joint European Science Foundation/European Commission scientific programme, funded by the EU and by national contributions from Belgium, Denmark, France, Germany, Italy, the Netherlands, Norway, Sweden, Switzerland and the UK. The main logistic support was provided by IPEV and PNRA (at Dome C) and AWI (at Dronning Maud Land). This is EPICA publication no. 280. We thank H. Stosch and an anonymous reviewer for helpful and constructive comments. We thank P. Vallelonga for assistance with the manuscript. A. Wegner thanks DFG for funding.

Edited by: D.-D. Rousseau 


\section{References}

Blunier, T., Schwander, J., Stauffer, B., Stocker, T., Daellenbach, A., Indermuehle, A., Tschumi, J., Chappellaz, J., Raynaud, D., and Barnola, J.: Timing of the Antarctic Cold Reversal and the Atmospheric $\mathrm{CO}_{2}$ Increase with Respect to the Younger Dryas Event, Geophys. Res. Lett., 24, 2683-2686, doi:10.1029/97GL02658, 1997.

Bory, A., Wolff, E., Mulvaney, R., Jagoutz, E., Wegner, A., Ruth, U., and Elderfield, H.: Multiple sources supply eolian mineral dust to the Atlantic sector of coastal Antarctica: Evidence from recent snow layers at the top of Berkner Island ice sheet, Earth Planet. Sc. Lett., 291, 138-148, doi:10.1016/j.eps1.2010.01.006, 2010.

De Deckker, P., Norman, M., Goodwin, I. D., Wain, A., and Gingele, F. X.: Lead isotopic evidence for an Australian source of Aeolian dust to Antarctica at times over the last 170000 years, Palaeogeogr. Palaeocl., 285, 205-223, doi:10.1016/j.palaeo.2009.11.013, 2010.

Delmonte, B.: Quaternary origin and variations of continental dust in East Antarctica, Ph.D Thesis, University of Siena, Siena, Italy, Universite Joseph Fourier-Grenoble I, Grenoble, France, 2003.

Delmonte, B., Petit, J. R., Andersen, K. K., Basile-Doelseh, I., Maggi, V., and Lipenkov, V. Y.: Dust size evidence for opposite regional atmospheric circulation changes over east Antarctica during the last climatic transition, Clim. Dynam., 23, 427438, doi:10.1007/s00382-004-0450-9, 2004a.

Delmonte, B., Basile-Doelsch, I., Petit, J.-R., Maggi, V., Revel-Rolland, M., Michard, A., Jagoutz, E., and Grousset, F.: Comparing the Epica and Vostok dust records during the last 220,000 years: stratigraphical correlation and provenance in glacial periods, Earth.-Sci. Rev., 66, 63-87, doi:10.1016/j.earscirev.2003.10.004, 2004b.

Delmonte, B., Andersson, P. S., Hansson, M., Schoeberg, H., Petit, J., Basile-Doelsch, I., and Maggi, V.: Aeolian dust in East Antarctica (EPICA-Dome C and Vostok): Provenance during glacial ages over the last $800 \mathrm{kyr}$, Geophys. Res. Lett., 35, L07703, doi:10.1029/2008GL033382, 2008.

Delmonte, B., Andersson, P. S., Schoeberg, H., Hansson, M., Petit, J. R., Delmas, R., Gaiero, D. M., Maggi, V., and Frezzotti, M.: Geographic provenance of aeolian dust in East Antarctica during Pleistocene glaciations: preliminary results from Talos Dome and comparison with East Antarctic and new Andean ice core data, Quaternary Sci. Rev., 29, 256-264, doi:10.1016/j.quascirev.2009.05.010, 2010a.

Delmonte, B., Andersson, P. S., Schoberg, H., Hansson, M., Aciego, S., Petit, J.-R., Albani, S., Mazzola, C., Maggi, V., and Frezzotti, M.: Aeolian dust in the Talos Dome ice core (East Antarctica, Pacific/Ross Sea sector): Victoria Land versus remote sources over the last two climate cycles, J. Quaternary Sci., 25, 1327-1337, doi:10.1002/jqs.1418, 2010b.

Dick, D., Wegner, A., Gabrielli, P., Barbante, C., Ruth, U., and Kriews, M.: ICP-Time of Flight-MS as a versatile tool for ultra trace element analysis in Antarctic ice, Anal. Chim. Acta, 621, 140-147, doi:10.1016/j.aca.2008.05.026, 2008.

EPICA Community Members: One-to-one coupling of glacial climate variability in Greenland and Antarctica, Nature, 444, 195198, doi:10.1038/nature05301, 2006.
Fischer, H., Fundel, F., Ruth, U., Twarloh, B., Wegner, A., Udisti, R., Becagli, S., Castellano, E., Morganti, A., Severi, M., Wolff, E., Littot, G., Roethlisberger, R., Mulvaney, R., Hutterli, M. A., Kaufmann, P., Federer, U., Lambert, F., Bigler, M., Hansson, M., Jonsell, U., de Angelis, M., Boutron, C., SiggaardAndersen, M. L., Steffensen, J. P., Barbante, C., Gaspari, V., Gabrielli, P., and Wagenbach, D.: Reconstruction of millenial changes in the dust emission, transport and regional sea ice coverage using the deep EPICA ice cores from the Atlantic and the Indian sector of Antarctica, Earth Planet. Sc. Lett., 260, 340-354, doi:10.1016/j.eps1.2007.06.014, 2007.

Gabrielli, P., Barbante, C., Boutron, C., Cozzi, G., Gaspari, V., Planchon, F., Ferrari, C., Turetta, C., Hong, S., and Cescon, P.: Variations in atmospheric trace elements in Dome C (East Antarctica) ice over the last two climatic cycles, Atmos. Environ., 39, 64206429, doi:10.1016/j.atmosenv.2005.07.025, 2005a.

Gabrielli, P., Planchon, F. A. M., Hong, S. M., Lee, K. H., Do Hur, S., Barbante, C., Ferrari, C. P., Petit, J. R., Lipenkov, V. Y., Cescon, P., and Boutron, C. F.: Trace elements in Vostok Antarctic ice during the last four climatic cycles, Earth Planet. Sc. Lett., 234, 249-259, doi:10.1016/j.epsl.2005.03.001, 2005b.

Gabrielli, P., Barbante, C., Turetta, C., Marteel, A., Boutron, C., Cozzi, G., Cairns, W., Ferrari, C., and Cescon, P.: Direct determination of rare earth elements at the subpicogram per gram level in antarctic ice by ICP-SFMS using a desolvation system, Anal. Chem., 78, 1883-1889, doi:10.1021/ac0518957, 2006.

Gabrielli, P., Wegner, A., Petit, J.-R., Delmonte, B., De Deckker, P., Gaspari, V., Fischer, H., Ruth, U., Kriews, M., Boutron, C., Cescon, P., and Barbante, C.: A major glacial-interglacial change in aeolian dust composition inferred from Rare Earth Elements in Antarctic ice, Quaternary Sci. Rev., 29, 265-273, doi:10.1016/j.quascirev.2009.09.002, 2010.

Gaiero, D. M.: Dust provenance in Antarctic ice during glacial periods: From where in southern South America?, Geophys. Res. Lett., 34, L17707, doi:10.1029/2007GL030520, 2007.

Gaiero, D. M., Depetris, P. J., Probst, J., Bidart, S. M., and Leleyter, L.: The signature of river- and wind-borne materials exported from Patagonia to the southern latitudes: a view from REEs and implications for paleoclimatic interpretations, Earth Planet. Sc. Lett., 219, 357-376, doi:10.1016/S0012-821X(03)00686-1, 2004.

Gaspari, V., Barbante, C., Cozzi, G., Cescon, P., Boutron, C. F., Gabrielli, P., Capodaglio, G., Ferrari, C., Petit, J. R., and Delmonte, B.: Atmospheric iron fluxes over the last deglaciation: Climatic implications, Geophys. Res. Lett., 33, L03704, doi:10.1029/2005GL024352, 2006.

Gaudichet, A., Petit, J., Lefevre, R., and Lorius, C.: An investigation by analytical transmission electron microscopy of individual insoluble microparticles from Antarctic (Dome C) ice core samples, Tellus B, 38, 250-261, 1986.

Gaudichet, A., De Angelis, M., Lefevre, R., Petit, J., Korotkevitch, Y. S., and Petroy, V. N.: Mineralogy of insoluble particles in the Vostok Antarctic ice core over the last climatic cylce (150 kyr), Geophys. Res. Lett., 15, 1471-1474, doi:10.1029/GL015i013p01471, 1988.

Kamber, B. S., Greig, A., and Collerson, K. D.: A new estimate for the composition of weathered young upper continental crust from alluvial sediments, Queensland, Australia, Geochim. Cosmochim. Acta, 69, 1041-1058, doi:10.1016/j.gca.2004.08.020, 
2005.

Kaufmann, P. R., Federer, U., Hutterli, M., Bigler, M., Schuepbach, S., Ruth, U., Schmitt, J., and Stocker, T.: An Improved Continuous Flow Analysis System for High-Resolution Field Measurements on Ice Cores, Environ. Sci. Technol., 42, 8044-8050, doi:10.1021/es8007722, 2008.

Lambert, F., Delmonte, B., Petit, J. R., Bigler, M., Kaufmann, P. R., Hutterli, M. A., Stocker, T. F., Ruth, U., Steffensen, J. P., and Maggi, V.: Dust-climate couplings over the past 800,000 years from the EPICA Dome C ice core, Nature, 452, 616-619, doi:10.1038/nature06763, 2008.

Lamy, F., Kaiser, J., Ninnemann, U., Hebbeln, D., Arz, H., and Stoner, J.: Antarctic timing of surface water changes off Chile and Patagonian ice sheet response, Science, 304, 1959-1962, doi:10.1126/science.1097863, 2004.

Lanci, L., Delmonte, B., Maggi, V., Petit, J. R., and Kent, D. V.: Ice magnetization in the EPICA-Dome $\mathrm{C}$ ice core: Implication for dust sources during glacial and interglacial periods, J. Geophys. Res., 113, D14207, doi:10.1029/2007JD009678, 2008.

Li, F., Ginoux, G., and Ramaswamy, V.: Distribution, transport, and deposition of mineral dust in the Southern Ocean and Antarctica: Contribution of major sources, J. Geophys. Res., 113, D10207, doi:10.1029/2007JD009190, 2008.

Mahowald, N., Albani, S., Engelstaedter, S., Winckler, G., and Goman, M.: Model insight into glacial interglacial paleodust records, Quaternary Sci. Rev., 30, 832-854, doi:10.1016/j.quascirev.2010.09.007, 2011.

Marino, F., Castellano, E., Ceccato, D., De Deckker, P., Delmonte, B., Ghermandi, G., Maggi, V., Petit, J., Revel Rolland, M., and Udisti, R.: Defining the geochemical composition of the EPICA Dome $\mathrm{C}$ ice core dust during the last glacial-interglacial cycle, Geochem. Geophy. Geosy., 9, Q10018, doi:10.1029/2008GC002023, 2008.

Marino, F., Castellano, E., Nava, S., Chiari, M., Ruth, U., Wegner, A., Lucarelli, F., Udisti, R., Delmonte, B., and Maggi, V.: Coherent composition of glacial dust on opposite sides of the East Antarctic Plateau inferred from the deep EPICA ice cores, Geophys. Res. Lett., 36, L23703, doi:10.1029/2009GL040732, 2009.

Marx, S. K., Kamber, B. S., and McGowan, H. A.: Provenance of long-travelled dust determined with ultra-trace-element composition: a pilot study with samples from New Zealand glaciers, Earth Surf. Proc. Land., 30, 699-716, doi:10.1002/esp.1169, 2005.

Reijmer, C. H., van den Broeke, M. R., and Scheele, M. P.: Air parcel trajectories to five deep drilling locations on Antarctica, based on the ERA-15 data set, J. Climate, 15, 1957-1968, 2002.

Revel-Rolland, M., De Deckker, P., Delmonte, B., Hesse, P. P., Magee, J. W., Basile-Doelsch, I., Grousset, F., and Bosch, D.: Eastern Australia: A possible source of dust in East Antarctica interglacial ice, Earth Planet. Sc. Lett., 249, 1-13, doi:10.1016/j.epsl.2006.06.028, 2006.
Roethlisberger, R., Bigler, M., Hutterli, M., Sommer, S., Stauffer, B., Junghans, H. G., and Wagenbach, D.: Technique for continuous high-resolution analysis of trace substances in firn and ice cores, Environ. Sci. Technol., 34, 338-342, 2000.

Roethlisberger, R., Mulvaney, R., Wolff, E. W., Hutterli, M. A., Bigler, M., Sommer, S., and Jouzel, J.: Dust and sea salt variability in central East Antarctica (Dome C) over the last 45 kyrs and its implications for southern high-latitude climate, Geophys. Res. Lett., 29, 1963, doi:10.1029/2002GL015186, 2002.

Rudnick, R. L. and Gao, S.:Composition of the continental crust, in: The Crust, Vol. 3 Treatise on Geochemistry, edited by: Holland, H. D., Turekian, K. K., and Rudnick, R. L., Elsevier Pergamon, Oxford, 1-64, 2005.

Severi, M., Becagli, S., Castellano, E., Morganti, A., Traversi, R., Udisti, R., Ruth, U., Fischer, H., Huybrechts, P., Wolff, E., Parrenin, F., Kaufmann, P., Lambert, F., and Steffensen, J. P.: Synchronisation of the EDML and EDC ice cores for the last $52 \mathrm{kyr}$ by volcanic signature matching, Clim. Past, 3, 367-374, doi:10.5194/cp-3-367-2007, 2007.

Siggaard-Andersen, M. L., Gabrielli, P., Steffensen, J. P., Stromfeldt, T., Barbante, C., Boutron, C., Fischer, H., and Miller, H.: Soluble and insoluble lithium dust in the EPICA Dome $\mathrm{C}$ ice core - Implications for changes of the East Antarctic dust provenance during the recent glacial-interglacial transition, Earth Planet. Sc. Lett., 258, 32-43, doi:10.1016/j.eps1.2007.03.013, 2007.

Smith, J., Vance, D., Kemp, R. A., Archer, C., Toms, P., King, M., and Zarate, M.: Isotopic constraints on the source of Argentinian loess - with implications for atmospheric circulation and the provenance of Antarctic dust during recent glacial maxima, Earth Planet. Sc. Lett., 212, 181-196, doi:10.1016/S0012821X(03)00260-7, 2003.

Sugden, D. E., McCulloch, R. D., Bory, A. J., and Hein, A. S.: Influence of Patagonian glaciers on Antarctic dust deposition during the last glacial period, Nat. Geosci., 2, 281-285, doi:10.1038/NGEO474, 2009.

Vallelonga, P., Gabrielli, P., Balliana, E., Wegner, A., Delmonte, B., Turetta, C., Burton, G., Vanhaecke, F., Rosman, K. J. R., Hong, S., Boutron, C. F., Cescon, P., and Barbante, C.: Lead isotopic compositions in the EPICA Dome $\mathrm{C}$ ice core and Southern Hemisphere Potential Source Areas, Quaternary Sci. Rev., 29, 285-295, doi:10.1016/j.quascirev.2009.06.019, 2010.

Winckler, G. and Fischer, H.: 30000 Years of Cosmic Dust in Antarctic Ice, Science, 313, 491, doi:10.1126/science.1127469, 2006. 